\title{
MAXIMUMECONOMIC YIELD PERIKANAN TANGKAP PELAGIS KECIL DI WPPNRI 711
}

\author{
Djamarel Hermanto ${ }^{a}, *$ Tridoyo Kusumastanto ${ }^{a}$, Luky Adrianto ${ }^{a}$, Supartono ${ }^{b}$ \\ ${ }^{a}$ Sekolah Pascasarjana, Institut Pertanian Bogor, Kampus IPB Darmaga, Bogor 16680, Indonesia \\ bUniversitas Pertahanan Indonesia, Kompleks IPSC, Sentul Bogor 16810, Indonesia \\ *Corresponding author:djamare188@gmail.com
}

\begin{abstract}
Abstrak
Penelitian ini bertujuan untuk mengetahui jumlah hasil tangkapan pelagis kecil yang optimal dilihat dari segi ekonomi dengan tetap berdasarkan pada keberlanjutan pemanfaatan perikanan tangkap. Penelitian ini dilakukan di Wilayah Pengelolaan Perikanan Negara Republik Indonesia (WPPNRI) 711 yang kaya akan pelagis kecil dan merupakan wilayah yang rawan kegiatan illegal fishing, dengan menggunakan data primer dan data sekunder. Data primer diperoleh melalui wawancara dengan nelayan lokal dan pengawas kelautan. Sedangkan data sekunder diperoleh dari Kantor Kementerian Kelautan dan Perikanan (KKP) Republik Indonesia, Kantor Komando Armada RI Wilayah Barat dan Kantor Badan Keamanan Laut Republik Indonesia. Data sekunder dianalisis selama sebelas tahun mulai tahun 2005 sampai dengan tahun 2016. Pendekatan analisis data menggunakan model Gordon Schaefer dan untuk analis is manfaat ekonominya menggunakan model surplus produksi Fox dalam penelitian ini. Manfaat optimal pengelolaan ekonomi perikanan tangkap pelagis kecil di WPPNRI 711 adalah upaya penangkapan 5.040 unit kapal, hasil tangkapan $13.560,3$ ton per tahun dan rente ekonomi 225,50 miliar rupiah per tahun. Tingkat pengelolaan yang dilakukan oleh nelayan baik dilihat dari usaha maupun hasil tangkapan yang didaratkan menunjukkan kondisi masih dibawah tingkat optimum sehingga masih dapat ditingkatkan upaya penangkapan dan hasil tangkapannya dengan tetap memperhatikan prinsip kehati-hatian dalam pengelolaan ekonomi perikanan tangkap pelagis kecil tersebut.
\end{abstract}

Keywords: maksimum economic yield, pelagis kecil, perikanan tangkap, WPPNRI 711

\begin{abstract}
This research aims to calculate small pelagic optimum exploitation in economic term based on the sustainable use of fisheries. The research conducted in Regional Fisheries Management Republic of Indonesia (WPPNRI) 711 is rich small pelagic and areas that are prone to illegal fishing activities, using primary data and secondary data. Primary data were collected from interviews with local fishermen and marine superintendent using interview technique. While secondary data obtained from the Ministry of Marine Affairs and Fisheries (MMAF) Republic of Indonesia, the Indonesian Fleet Command Office of the Western Region and the Office of Maritime Security Agency of Indonesia. Data time series of 2005 to 2016 were also analyzed. Bioeconomic analysis using a model for the analysis of Gordon Schaefer and economic benefits using surplus production model developed by Fox in this study. Optimum economic exploitation of small pelagic fishery management in WPPNRI 711 is 5.040 fishing ships effort, 13.560,30 tons per year productions and 225,50 billion rupiahs economic rent per year. Exploitation rate carried out by fishermen either viewed from the business as well as the catch landed indicates the condition is still below the optimum level so that they can be developed with due regard to the principles of prudence in fisheries economic management of the Small Pelagic.
\end{abstract}

Keywords: capture fisheries, maximum economic yield, small pelagic, WPPNRI 711

\section{PENDAHULUAN}

Indonesia sebagai negara kepulauan terbesar di dunia [1] yang memiliki jumlah pulau mencapai 17.499 pulau. Data mengenai Wilayah Negara Kesatuan Republik Indonesia berdasarkan publikasi resmi [2], dengan luas perairan Indonesia 3,25 juta $\mathrm{km}^{2}$ yang terdiri dari luas laut teritorial 0,30 juta $\mathrm{km}^{2}$ dan luas laut kepulauan 2,95 juta $\mathrm{km}^{2}$. Luas Zona Ekonomi Ekslusif (ZEE) Indonesia 2,55 juta $\mathrm{km}^{2}$. Panjang garis pantai yang tercatat 
sebagai bagian wilayah Indonesia mencapai $81.791 \mathrm{~km}$. Dari data tersebut terkandung potensi kekayaan laut Indonesia yang amat besar dan dapat dimanfaatkan untuk kesejahteraan rakyat Indonesia. Potensi sumberdaya kelautan yang dimiliki oleh bangsa Indonesia terdiri atas sumberdaya yang dapat diperbaharui seperti sumberdaya perikanan (perikanan tangkap, budidaya) dan sumberdaya yang tidak dapat diperbaharui seperti minyak dan gas bumi serta berbagai jenis mineral [3].

Menurut [4], untuk menjadikan kelautan sebagai leading sector dalam pembangunan maka pendekatan kebijakan yang dilakukan harus mempertimbangkan keterkaitan antar sektor ekonomi dalam lingkup bidang kelautan. Untuk itu dalam perencanaan pembangunan serta implementasinya, peran koordinasi antar institusi pemerintah sangat penting agar dapat mempercepat peningkatan peran sumberdaya kelautan dalam memperkokoh perekonomian nasional dalam era yang sangat kompetitif. Oleh karenanya menurut [5], perikanan memiliki peranan penting dalam penyediaan bahan pangan, kesempatan kerja, rekreasi, perdagangan dan kesejahteraan ekonomi, tidak hanya bagi masyarakat di sekitar lingkungan sumberdaya, tetapi juga meliputi suatu kawasan atau komunitas tertentu. Karena itu sumberdaya perikanan membutuhkan pengelolaan yang berorientasi pada kepentingan jangka panjang (sustainable). Tidak hanya bagi generasi saat ini namun juga generasi masa depan mendapatkan hasil manfaat dari laut.

Analisis sensitivitas terhadap dimensi ekonomi berpengaruh terhadap nilai indeks keberlanjutan dimensi ekonomi [6]. Berarti membuktikan bahwa keberlanjutan perikanan tangkap, khususnya pelagis kecil juga dipengaruhi sensitivitas lingkungannya.

Menurut [7], sumberdaya ikan dibagi berdasarkan habitatnya, ikan pelagis merupakan ikan yang hidup pada lapisan permukaan perairan sampai tengah (mid layer). Ikan pelagis umumnya hidup secara bergerombol baik dengan kelompok maupun dengan jenis ikan lain. Ikan pelagis bersifat fototaxis positif dan tertarik pada benda-benda terapung. Bentuk tubuh ikan menyerutu (stream line) dan merupakan perenang cepat [8]. Jenis ikan yang dianalisis dalam penelitian ini adalah kelompok ikan pelagis kecil yaitu, Banyar, Belanak, Bentong, Cendro, Daun Bambu/ Talang-talang, Ikan terbang, Japuh, Julung-julung, Kembung, Layang, Lemuru, Selanget, Selar, Siro, Sunglir, Tembang, Teri, Terubuk, Tetengkek dan Lainnya [9]. Di Indonesia, ikan pelagis kecil merupakan salah satu sumberdaya perikanan yang paling melimpah dan banyak ditangkap untuk dijadikan konsumsi masyarakat Indonesia dari berbagai kalangan bila dibandingkan dengan jenis pelagis lainnya. Kondisi ini pula yang mendorong maraknya kegiatan penangkapan ilegal guna mencukupi kebutuhan akan konsumsi ikan pelagis kecil di tanah air maupun di luar negeri.

Wilayah Pengelolaan Perikanan Negara Republik Indonesia terdiri dari sebelas wilayah pengelolaan perikanan (WPPNRI) [10], salah satunya adalah WPPNRI 711 yang menjadi lokasi obyek penelitian penulis. Perairan ini secara geografis memiliki nilai arti strategis karena terletak di wilayah perbatasan dengan Malaysia, Singapura, Thailand, Filipina dan Vietnam. Kondisi ini menarik banyaknya nelayan-nelayan asing yang masuk ke perairan Indonesia untuk memanfaatkan secara ekonomi sumberdaya perikanan tangkap yang terdapat di perairan ini. WPPNRI 711 meliputi Perairan Selat Karimata, Laut Cina Selatan dan Laut Natuna juga mempunyai batas-batas langsung dengan negara tetangga seperti Malaysia, Singapura, Thailand dan Vietnam [11]. Sehingga kegiatan illegal fishing tersebut mengurangi produksi perikanan nasional dan hasil tangkapan nelayan.

Berdasarkan data [12], bahwa pada tahun 2012, PDB (Pendapatan Domestik Bruto) dari sektor perikanan Indonesia adalah Rp 184,25 triliun dan berkontribusi sebesar 2,14 persen terhadap PDB nasional. Pada tahun 2013, kontribusinya meningkat menjadi 2,21 persen terhadap PDB nasional, dan terus meningkat di tahun 2014 dengan nilai sebesar Rp 247,09 triliun atau berkontribusi sebesar 2,34 persen terhadap PDB nasional. Sedangkan pada tahun 2015, dengan nilai sebesar Rp 288,92 
triliun dengan kontribusi 2,51 persen dan tahun 2016 sebesar Rp 317,09 triliun rupiah dengan kontribusi sebesar 2,56 persen.

\section{METODE PENELITIAN}

Metode yang digunakan dalam penelitian ini adalah metode studi kasus (case study) yaitu pengelolaan ekonomi perikanan, dan menurut [13] bahwa penelitian pengelolaan ekonomi perikanan merupakan penelitian tentang status subjek penelitian yang berkenan dengan suatu fase spesifik atau khas dari keselurahan personalitas. Subjek penelitian dapat berupa individu, kelompok, lembaga, maupun masyarakat.

Tujuan studi kasus adalah untuk memberikan gambaran secara mendetail latar belakang, sifat-sifat serta karakter-karakter yang khas dari kasus, ataupun status dari individu, yang kemudian dari sifat-sifat khas di atas akan dijadikan suatu hal yang bersifat umum. Hasil dari penelitian kasus merupakan suatu generalisasi dari pola-pola kasus yang tipikal dari individu, kelompok, lembaga, dan sebagainya. Tergantung dari tujuannya, ruang lingkup dari studi dapat mencakup segmen atau bagian tertentu atau mencakup keseluruhan siklus kehidupan dari individu, kelompok, dan sebagainya, baik dengan penekanan terhadap faktor-faktor kasus tertentu, atau meliputi keseluruhan faktorfaktor dan fenomena-fenomena [13].

Lokasi penelitian ini dilakukan di WPPNRI 711, stasiun pengawas KKP Pontianak, pangkalan TNI AL (Gambar 1). Alasan pertimbangan pemilihan lokasi adalah perairan di wilayah ini memiliki potensi ikan paling tinggi sebagai fishing ground penangkapan legal juga sekaligus wilayah rawan penangkapan ilegal. Perairan ini, juga menjadi titik pertemuan antara arus hangat dan arus dingin yang membuatnya menarik bagi berbagai jenis ikan.

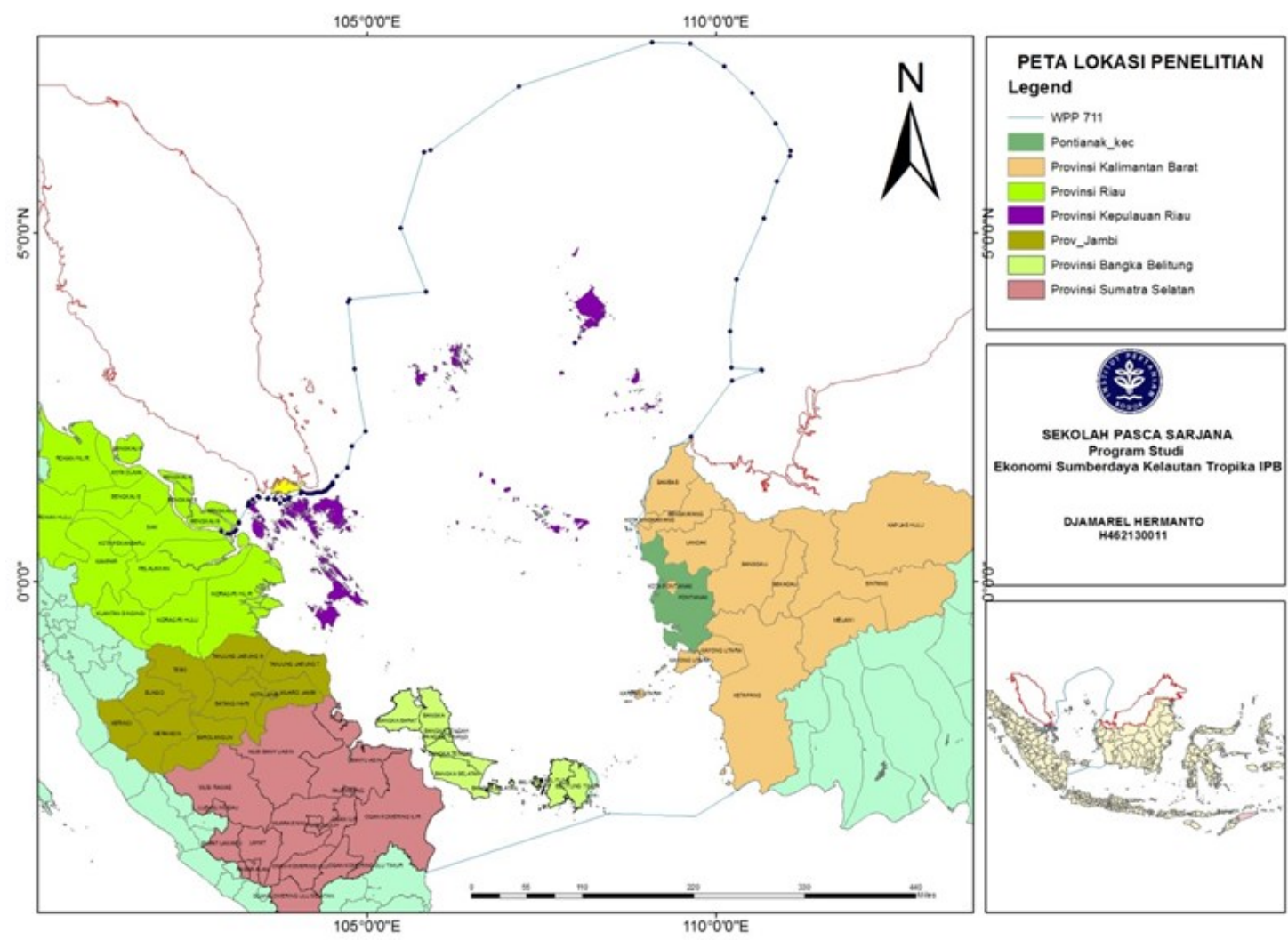

Gambar 1. Lokasi penelitian di WPPNRI 711 
Data produksi tangkapan dan upaya penangkapan diolah dari tangkapan legal dan illegal berdasarkan time series periode tahun 2005 sampai tahun 2016. Penelitian berlangsung selama empat bulan dimulai dari bulan Agustus 2017 sampai dengan bulan Nopember 2017.

Model yang digunakan dalam penelitian ini adalah model surplus produksi yang merupakan pengembangan model biologi Shaefer. Bentuk umum model biologi Schaefer dalam [14] adalah:

$$
\frac{d x}{d t}=r x\left(1-\frac{x}{K}\right)-h
$$

dimana:

$\mathrm{x}=$ stock ikan atau fish stock

$\mathrm{r}=$ laju pertumbuhan instrinsik atau intrinsic growth rate

$\mathrm{K}=$ daya dukung lingkungan atau carrying capacity

$\mathrm{h}=$ hasil tangkapan atau harvest

Model dasar tersebut merupakan fungsi produksi perikanan dengan mengasumsikan bahwa produksi per unit upaya atau catch per unit effort bersifat proporsional terhadap tingkat stok (biomass). Sehingga fungsi produksi perikanan dituliskan sebagai berikut [14]:

$$
h=q x E
$$

dimana:

$\mathrm{q}=$ koefisien kemampuan penagkapan atau catchability coeficien

$\mathrm{E}=$ upaya penangkapan atau effort

Dengan mengasumsikan kondisi keseimbangan jangka panjang (long run equilibrium) dimana $\frac{d x}{d t}=0$ maka dapat dipecahkan untuk x dalam bentuk:

$$
x=K\left[1-\frac{q E}{r}\right]
$$

Persamaan ini menggambarkan variabel stok (x) sebagai fungsi dari parameter biofisik $(\mathrm{q}, \mathrm{K}, \mathrm{r})$ dan variabel input $(\mathrm{E})$.

Dengan mensubstitusi variabel $\mathrm{x}$ tersebut maka fungsi penagkapan dapat ditulis sebagai berikut:

$$
h=q K E\left[1-\frac{q E}{r}\right]
$$

Aspek ekonomi pengelolaan perikanan dengan berbasis model biologi Scaefer dan dikenal dengan model Gordon-Schaefer. Secara matematis penerimaan total lestari (TSR) dapat dituliskan [14], [15] sebagai berikut:

$$
T S R=p h=p q K E\left[1-\frac{q E}{r}\right]
$$

Dengan mengasumsikan bahwa biaya total (TC) bersifat linear terhadap input (effort) maka biaya total (TC) dapat ditulis:

$$
T C=c E
$$

dimana: $\mathrm{c}=$ konstanta

Maka manfaat ekonomi dari pengelolaan ekonomi perikanan tangkap pelagis di WPPNRI 711 dapat dihitung dari selisih antara penerimaan dan biaya dituliskan menjadi:

$$
\begin{aligned}
& \pi=T S R-T C \\
& \pi=p q K E\left[1-\frac{q E}{r}\right]-c E
\end{aligned}
$$

Dengan melihat fungsi keuntungan tersebut maka terdapat dua keseimbangan pengelolaan ekonomi perikanan tangkap secara efisien yaitu:

- Keseimbangan pertama dimana kurva TC berpotonan dengan kurva TSR pada satu titik effort (E $\sim$ ) yang disebut sebagai open access equalibrium atau keseimbangan perikanan dalam kondisi akses terbuka.

- Keseimbangan kedua dimana garis sejajar kurva TC dengan kurva TSR bersinggungan pada satu titik effort $\left(\mathrm{E}^{*}\right)$ yang disebut sebagai keseimbangan maximum economc yield (MEY) dalam kondisi perikanan dikendalikan dengan rezim kepemilikan yang jelas.

Penerimaan rata-rata atau Average Sustainable Revenue (ASR) dapat ditulis sebagai berikut:

$$
A S R=\frac{T S R}{E}=p q K-\frac{p q^{2} K E}{r}
$$


Dan penerimaan marjinalnya atau Marginal Sustainable Revenue (MAR) dapat ditulis:

$$
M S R=\frac{\partial T S R}{\partial E}=p q K-2 \frac{p q^{2} K}{r} E
$$

Pada kondisi maximum economic yield, maka penerimaan marjinal sama dengan total biaya $(\mathrm{MSR}=\mathrm{TC})$ dapat dituliskan sebagai berikut:

$$
p q K-2 \frac{p q^{2} K}{r} E=c
$$

Dari persamaan diatas didapatkan jumlah upaya penangkapan optimal pada kondisi MEY yaitu:

$$
E^{*}=\frac{r}{2 q}\left[1-\frac{c}{p q K}\right]
$$

Bentuk Regresi Umum dirumuskan sebagai berikut:

$$
y=\alpha+\beta_{1} x_{1}+\beta_{2} x_{2}
$$

Untuk Regresi Perikanan Tangkap dirumuskan sebagai berikut:

$$
\begin{aligned}
& y=\operatorname{LnCPUE} E_{t+1} x_{1}=\operatorname{LnCPUE} E_{t} \\
& x_{2}=E_{t}+E_{t+1}
\end{aligned}
$$

Maka model analisis Gordon-Schaefer perikanan tangkap dapat dituliskan:

$$
\ln C P U E_{t+1}=\beta_{1}+\beta_{2} \operatorname{LnCPUE} t+\beta_{3}\left[E_{t}+E_{t+1}\right]
$$

\section{Analis is Penangkapan Optimal}

Metode analisis data berdasarkan model pendekatan yang telah dikemukakan sebelumnya terdiri dari mertode untuk pendugaan parameter-parameter yang digunakan dan metode untuk pendugaan nilai optimal pengelolaan ekonomi perikanan tangkap pelagis kecil di WPPNRI 711 pada rezim pengelolaan maximumeconomic yield.

Parameter fungsi produksi surplusnya yaitu parameter pertumbuhan intrinsik ikan (r), daya dukung lingkungan $(\mathrm{K})$ dan kemampuan alat tangkap dalam melakukan penangkapan ikan (q) [16], secara matematis dapat ditulis sebagai berikut:

$$
X_{t+1}=X_{t}+r X_{t}\left(1-\frac{X_{t}}{K}\right)-C_{t}
$$

dimana:

$$
C_{t}=q X_{t} E_{t}
$$

Jika:

$$
X_{t}=\frac{U_{t}}{q}
$$

Maka diperoleh CPUE (Catch Per Unit Effort):

$$
U_{t}=\frac{C_{t}}{E_{t}}
$$

Metode standarisasi [17] pada hubungan antara effort dan CPUE:

$$
\begin{aligned}
& \frac{C_{t}}{E_{t}}=e^{\left(a-b E_{t}\right)} \\
& C_{t}=E_{t} e^{\left(a-b E_{t}\right)}
\end{aligned}
$$

Effort optimal $\left(E_{\text {opt }}\right)$ diperoleh dengan cara menyamakan turunan pertama $C_{t}$ terhadap effort $=0$

$$
\frac{d C_{t}}{d E_{t}}=e^{\left(a-b E_{t}\right)}+E_{t} e^{\left(a-b E_{t}\right)}(-b)=0
$$

Sehingga didapat:

$$
E_{\text {opt }}=\frac{1}{b}
$$

Dan produksi maksimum lestari (MSY) diperoleh dengan mensubstitusikan nilai $E_{\text {opt }}$ kedalam persamaan $C_{t}=E_{t} e^{\left(a-b E_{t}\right)}$ didapat:

$$
M S Y=\frac{1}{b} e^{a / b-1}
$$

Pada Tabel 1 berikut ini, disampaikan data statistik produksi ikan pelagis kecil dan jumlah kapal ikan periode tahun 2005-2016 di WPPNRI 711. 
Tabel 1. Jumlah produksi dan upaya dari tangkapan legal dan illegal pelagis kecil di WPPNRI 711

\begin{tabular}{ccccccc}
\hline \multirow{2}{*}{ Tahun } & \multicolumn{3}{c}{ Produksi pelagis kecil (ton) } & \multicolumn{2}{c}{ Kapal ikan } & \multirow{2}{*}{$\begin{array}{c}\text { Upaya std } \\
\text { (unit kapal) }\end{array}$} \\
\cline { 2 - 5 } & Legal Fishing & Illegal Fishing & Jumlah & Legal Fishing & Illegal Fishing & 8.740 \\
2005 & $8.719,58$ & $2.906,53$ & $11.626,10$ & 6.555 & 309 & 4.425 \\
2006 & $6.193,40$ & $3.334,91$ & $9.528,31$ & 2.876 & 282 & 5.783 \\
2007 & $8.234,36$ & $4.433,89$ & $12.668,25$ & 3.759 & 256 & 3.748 \\
2008 & $6.864,39$ & $3.696,21$ & $10.560,60$ & 2.436 & 230 & 3.767 \\
2009 & $8.494,71$ & $3.640,59$ & $12.135,30$ & 2.637 & 204 & 5.051 \\
2010 & $9.191,52$ & $4.949,28$ & $14.140,80$ & 3.283 & 181 & 4.279 \\
2011 & $10.048,05$ & $3.349,35$ & $13.397,40$ & 3.209 & 162 & 4.023 \\
2012 & $8.927,55$ & $2.975,85$ & $11.903,40$ & 3.017 & 146 & 5.126 \\
2013 & $13.886,64$ & $1.542,96$ & $15.429,60$ & 4.613 & 41 & 3.676 \\
2014 & $9.225,90$ & $1.628,10$ & $10.854,00$ & 3.125 & 65 & 3.869 \\
2015 & $10.370,70$ & $3.456,90$ & $13.827,60$ & 2.902 & 70 & 3.713 \\
2016 & $10.507,73$ & $3.502,58$ & $14.010,30$ & 2.785 & 24 & \\
\hline
\end{tabular}

\section{Analis is Illegal Fishing}

Illegal Fishing yaitu suatu tindak kejahatan menangkap ikan di wilayah laut suatu negara yang dilakukan secara tidak sah atau bersifat ilegal bentuk illegal fishing [18]. Usaha penangkapan ilegal menimbulkan kerugian atau mengurangi pendapatan yang seharusnya bisa didapatkan untuk meningkatkan hasil dan effort dalam pengelolaan ekonomi perikanan tangkap. Dalam analisa illegal fishing [19], [20] dimana seharusnya kerugian ini sebagai penambahan input dalam model pendekatan dan model surplus produksinya. Sehingga biaya total pengelolaan ekonomi perikanan tangkap, rumus biaya total (TC) menjadi:

$$
T C *=c\left(E+E_{i f}\right)
$$

Dan rumus kerugian ekonomi illegal fishing menjadi:

$$
\pi *=p h-c\left(E+E_{i f}\right)
$$

\section{HASIL DAN PEMBAHASAN}

Penentuan parameter biologi dalam pengelolaan ekonomi perikanan tangkap pelagis kecil di WPPNRI 711 memerlukan data hasil produksi dan jumlah kapal penangkap ikan tersebut dengan harves per effort. Untuk industri perikanan tangkap kapal penangkap ikan yang memiliki tonnase diatas 30 GT yang mampu memanfaatkan sumberdaya ikan secara produktif dan efisien di WPPNRI 711.

Tabel 2. Data analisa surplus produksi model Fox di WPPNRI 711

\begin{tabular}{cccc}
\hline Tahun & Tangkapan (ton) & Upaya (unit) & CPUE \\
\hline 2005 & $11.626,10$ & 8.740 & 1,330 \\
2006 & $9.528,31$ & 4.425 & 2,153 \\
2007 & $12.668,25$ & 5.783 & 2,191 \\
2008 & $10.560,60$ & 3.748 & 2,818 \\
2009 & $12.135,30$ & 3.767 & 3,221 \\
2010 & $14.140,80$ & 5.051 & 2,800 \\
2011 & $13.397,40$ & 4.279 & 3,131 \\
2012 & $11.903,40$ & 4.023 & 2,959 \\
2013 & $15.429,60$ & 5.126 & 3,010 \\
2014 & $10.854,00$ & 3.676 & 2,952 \\
2015 & $13.827,60$ & 3.869 & 3,574 \\
2016 & $14.010,30$ & 3.713 & 3,773 \\
\hline
\end{tabular}

Pada Tabel 2 diatas, terlihat bahwa hasil tangkapan tertinggi pada tahun 2013, dan hasil tangkapan terendah pada tahun 2006. Secara keseluruhan hasil tangkapan perikanan tangkap pelagis kecil di WPPNRI 711 terlihat adanya peningkatan hasil tangkapan oleh nelayan di WPPNRI 711 dari tahun 2005 sampi tahun 2016. Dijelaskan pula bahwa perkembangan upaya penangkapan ikan pelagis kecil di WPPNRI 711, tertinggi pada tahun 2005, dan terendah terjadi pada tahun 2008. Secara keseluruhan upaya penangkapan ikan oleh nelayan di WPPNRI 711 cukup fluktuatif.

Hasil perhitungan untuk parameter biologi ditabelkan pada Tabel 3 berikut ini. 
Tabel 3. Parameter Biologi Perikanan Tangkap Pelagis Kecil di WPPNRI 711

\begin{tabular}{clc}
\hline Koefisien & \multicolumn{1}{c}{ Definisi } & Nilai \\
\hline$R$ & Tingkat pertumbuhan & 0,28499087 \\
& Intrinsik & \\
$Q$ & Kemampuan Tangkap & 0,00002352 \\
$K$ & Daya Dukung Perairan & $195.860,52$ \\
\hline
\end{tabular}

Penentuan harga rata-rata ikan pelagis kecil yang ditangkap di WPPNRI 711 diperoleh dari data primer dan data sekunder. Data primer diperoleh dari hasil wawancara dengan nelayan, sedangkan data sekunder diperoleh dari statistik perikanan tangkap [21], [22].

Pada Tabel 4 dibawah ini, dijelaskan bahwa harga ikan pelagis kecil yang diperoleh dari data sekunder semejak tahun 2005 sampai tahun 2016 adalah rata-rata harga nominal setiap tahun. Supaya data tersebut dapat diperbandingkan setiap tahunnya maka yang digunakan adalah harga rill, yang diperoleh dari harga nominal dibagi dengan indeks harga konsumen dengan tahun dasar pada tahun 2010.

Tabel 4. Harga nominal, indeks harga konsumen dan harga riil

\begin{tabular}{cccc}
\hline \multirow{2}{*}{ Tahun } & \multicolumn{3}{c}{ Hasil Tangkapan } \\
\cline { 2 - 4 } & $\begin{array}{c}\text { Harga } \\
\text { Nominal (Rp) }\end{array}$ & $\begin{array}{c}\text { IHK } \\
\mathbf{2 0 1 0}=\mathbf{1 0 0}\end{array}$ & $\begin{array}{c}\text { Harga } \\
\text { Riil (Rp) }\end{array}$ \\
\hline 2005 & 21.382 & 94,15 & 22.711 \\
2006 & 21.964 & 95,42 & 23.027 \\
2007 & 22.553 & 96,69 & 23.324 \\
2008 & 23.150 & 97,97 & 23.631 \\
2009 & 23.765 & 99,24 & 23.948 \\
2010 & 24.122 & 100 & 24.122 \\
2011 & 21.194 & 93,74 & 22.611 \\
2012 & 21.673 & 94,79 & 22.865 \\
2013 & 22.459 & 96,47 & 23.270 \\
2014 & 22.553 & 96,69 & 23.324 \\
2015 & 22.459 & 96,47 & 23.270 \\
2016 & 24.158 & 100,06 & 24.145 \\
Harga & 22.616 & & 25.000 \\
rata-rata & & & \\
\hline
\end{tabular}

\section{Pendugaan Nilai Optimal}

Tingkat eksploitasi perikanan tangkap pelagis kecil yang optimal diperoleh dengan bantuan program Excel, seperti yang dikemukakan [23]. Nilai tersebut dapat ditentukan setelah diketahui parameter biologi [24] dan juga parameter ekonomi yang telah dikemukakan sebelumnya. Dengan menggunakan persamaan sebelumnya maka dapat diketahui tingkat biomas optimal pelagis kecil di WPPNRI 711 adalah 114.392,10 ton per tahun. Dari jumlah biomas tersebut, maximum economic pelagis kecil yang boleh dimanfaatkan atau ditangkap sebesar 13.9560,30 ton per tahun. Jumlah trip yang boleh beroperasi untuk menangkap pelagis kecil adalah 5.040 unit kapal.

Berdasarkan data jumlah rata-rata produksi pelagis kecil di WPPNRI 711 sebesar $12.506,81$ ton dan upaya tangkap sebesar 4.684 unit kapal, menunjukan bahwa tingkat pemanfaatan ekonomi perikanan tangkap pelagis kecil masih dibawah maximum economic. Dan pada Tabel 5, dijelaskan bahwa dengan jumlah upaya penangkapan pada maximum economic yaitu 5.040 unit kapal dengan hasil tangkapan sebesar $13.560,3$ ton akan diperoleh nilai manfaat atau rente ekonomi sekitar 225,5 miliar rupiah per tahun.

Tabel 5. Maximum economic dan aktual perikanan tangkap pelagis kecil di WPPNRI 711

\begin{tabular}{llrr}
\hline \multicolumn{1}{c}{ Simbol } & Definisi & \multicolumn{1}{c}{ Optimal } & \multicolumn{1}{c}{ Aktual } \\
\hline $\mathrm{x}$ (ton) & Biomass & $114.392,10$ & - \\
$\mathrm{h}^{*}$ (ton) & Tangkapan & $13.560,30$ & $12.506,81$ \\
$\mathrm{E}^{*}$ (unit) & Upaya trip & 5.040 & 4.683 \\
$\Pi$ (juta Rp) & Rente & $225.501,54$ & $207.398,58$ \\
\hline
\end{tabular}

\section{KESIMPULAN}

Pengelolaan ekonomi perikanan tangkap pelagis kecil di WPPNRI dapat ditingkatkan mencapai tingkat optimal pada rejim pengelolaan Maximum Economic Yield (MEY).

Kondisi penangkapan aktual adalah 4.683 unit kapl dengan hasil tangkapan 12.506,81 ton, sedangkan jumlah upaya penangkapan optimal secara ekonomi adalah 50.40 unit kapal dengan hasil tangkapan 13.560,30 ton.

Hasil dari penelitian ini menunjukkan kondisi tangkap masih dibawah tingkat optimum sehingga tingkat pemanfaatan dapat dilakukan pada kondisi optimal dan rente ekonomi maksimum dapat dicapai untuk 
mensejahterakan nelayan perikanan tangkap pelagis kecil di WPPNRI 711.

\section{DAFTAR PUSTAKA}

[1] J. Rewis, Menjahit laut yang robek paradigma archipelago state Indonesia. Yayasan Malesung. Jakarta. 2004.

[2] Pushidrosal (Pusat Hidrografi dan Oseanografi Tentara Nasional Indonesia-Angkatan Laut). Data wilayah Negara Kesatuan Republik Indonesia. Pushidrosal. Jakarta. 2012.

[3] T. Kusumastanto. Ekonomi Kelautan (Ocean Economics-Oceanomics). PKSPL-IPB. Bogor. 2006.

[4] T. Kusumastanto. Ocean policy dalam membangun negeri bahari di era otonomi daerah. Gramedia Pustaka Utama. Jakarta. 2003.

[5] L. Adrianto, Y. Matsuda, and Y. Sukuma. "Assessing local fisheries sustainability of fisheries system: a multi-criteria participatory approach with the case of Yoron Island," Marine policy, vol. 29, no. 1, hal. 9-23, Jan 2005.

[6] Theresia. "Status keberlanjutan pengelolaan ekosistem mangrove di Taman Nasional Sembilang kabupaten Banyuasin provinsi Sumatera Selatan," J. Ilmu dan Teknologi Kelautan Tropis, vol. 7, no. 2, hal. 703-714, Des 2015.

[7] V.P.H. Nikijuluw. Rezim pengelolaan sumberdaya perikanan. Penerbit Pusat Pemberdayaan dan Pembangunan Regional (P3R). Pustaka Cidesindo. Jakarta. 2002.

[8] I. Mukhsin. Pengelolaan sumberdaya hayati pesisir dan laut. Jurusan Manajemen Sumberdaya Perairan. Fakultas Perikanan dan Ilmu Kelautan. Institut Pertanian Bogor. 112 hal. 2003.
[9] Direktorat Jenderal Perikanan Tangkap Kementerian Kelautan dan Perikanan (Ditjen PTKKP). 2016. Statistik perikanan tangkap di laut menurut Wilayah Pengelolaan Perikanan Negara Republik Indonesia. Jakarta.

[10] Permen KP (Peraturan Menteri Kelautan dan Perikanan). No. 18 Tahun 2014. Tentang Wilayah Pengelolaan Perikanan Negara Republik Indonesia (WPPNRI). Biro Hukum dan Organisasi KKP. Jakarta. 2014.

[11] EAFM (Ecosystem Approach to Fisheries Management). Kajian awal keragaan pendekatan ekosistem dalam pengelolaan perikanan di wilayah pengelolaan perikanan Indonesia. Pendekatan Ekosistem dalam Pengelolaan Perikanan di Indonesia. Jakarta. 176 hlm. 2011.

[12] BPS (Badan Pusat Statistik) Indonesia. Pendapatan Nasional Indonesia Tahun 2012-2016. BPS. Jakarta. 2017.

[13] M. Nazir. Metode penelitian. Cetakan Keempat. Gahlia Indonesia. Jakarta. 2009.

[14] M.B. Schaefer. "Some Aspects of the Dynamics of Populations Importance to the Management of Commercial Marine Fisheries," Bull. Inter-Am. Trop. Comm, vol. 1, no. 2, hal. 23-56. 1954.

[15] A. Fauzi, Ekonomi sumberdaya alam dan lingkungan; Teori dan Aplikasi. Gramedia Pustaka Utama. Jakarta. 2010.

[16] H. Gordon. "The Economic Theory of A Common Property Resource: The Fishery," J. Political Economics, vol. 62, hal. 124-142. 1954.

[17] W.W. Fox. "An Experimental Surplus Yield Model for Optimizing Exploitated Fish Population," Trans. Am. Fish. Soc., vol. 99, no. 1, hal. 80-88. 1970. 
[18] G.M. Tinungki. Evaluasi model produksi surplus dalam menduga hasil tangkapan maksimum lestari untuk menunjang kebijakan pengelolaan perikanan lemuru di Selat Bali. IPB Press. Bogor. 2005.

[19] Mabesal (Markas Besar TNI Angkatan Laut). Peranan TNI Angkatan Laut dalam menanggulangi illegal, unreported dan unregulated fishing. Mabesal. Jakarta. 2008.

[20] FAO (Food and Agriculture Organization). Implementation of the international plan of action to deter, prevent and eleminate illegal, unreported and unregulated fishing. FAO technical guidelines for responsible fisheries, vol. 9, hal. 122. 2002.
[21] D.J. Agnew, S.F. Walmsley, F. Leotte, C. Barnes, C. White, and S. Good. Estimation of the cost of illegal fishing in West Africa. West Africa Regional Fisheries Project, Marine Resources Assessment Group Ltd. Gambia. 97p. 2010.

[22] Ditjen PTKKP (Kementerian Kelautan dan Perikanan). Statistik perikanan tangkap Indonesi menurut provinsi. Ditjen PTKKP. Jakarta. 2015.

[23] A. Fauzi. Valuasi ekonomi dan penilaian kerusakan sumberdaya alam dan lingkungan. IPB Press. Bogor. 2014.

[24] A. Karman. "Basic biologi Cakalang sebagai landasan pengelolaan perikanan berkelanjutan di provinsi Maluku Utara," J. Ilmu dan Teknologi Kelautan Tropis, vol. 8, no. 1, hal. 159-173, Jun 2016. 